\title{
Prevalence and risk factors for Campylobacter infection of chicken in peri-urban areas of Nairobi, Kenya
}

\begin{abstract}
Campylobacter species are the most common bacterial causes of human gastroenteritis worldwide. A cross sectional study was done to determine the prevalence of Campylobacter in chicken and its associated risk factors in Nairobi between June and December 2015. Fifty six broiler chicken, one fifty four indigenous chicken and sixty two layers were included in the study. Cloacal swabs were obtained from live birds and Campylobacter status of the birds was determined using culture and multiplex polymerase chain reaction. Data on potential risk factors was collected by administering questionnaires to farmers in farms where cloacal swab samples were obtained. The overall prevalence of Campylobacter in this study was $69.5 \%$ with $91.07 \%$ in broiler chicken, $70.96 \%$ in layers and $61.04 \%$ in indigenous chickens. Approximately seventy seven percent $(76.8 \%)$ of the isolates from broiler chicken were found to be C. Jejuni and $14.3 \%$ were other Campylobacter species. No Campylobacter isolates from broilers were C. Coli. Thirty three percent $(32.5 \%)$ of the isolates from indigenous chicken were C. Jejuni , 5.84\% were C. Coli and 15.6\% were other Campylobacter species while $37.1 \%$ of the isolates from layers were C. Jejuni, $19.4 \%$ were C. Coli and $9.7 \%$ were untypable Campylobacter species. Logistic regression identified six variables as risk factors for Campylobacter colonization. They included old age of poultry house $(\mathrm{p}=0.23)$, large number of birds kept $(\mathrm{p}=0.12)$, increasing age of sale of birds $(p=0.01)$, type of rodent control $(p=0.03)$, inadequate washing and disinfection of poultry house before restocking $(\mathrm{p}=0.004)$ and absence of a medicated footbath at the entrance into the poultry house $(\mathrm{p}=0.05)$. These findings show that there is a high prevalence of Campylobacter infection in all kinds of chicken. The use of disinfected footbath at the entrance to the chicken house, adequate cleaning and disinfection of the chicken house, drinkers and feeders and proper rodent control measures will reduce chances of Campylobacter colonization in chickens. It was recommended that poultry farmers be educated on various insecurity measures that can reduce Campylobacter infection in chicken at farm level and the consequences of such infection.
\end{abstract}

Volume 7 Issue I - 2018

\author{
Lydia M Mageto, Jackson N Ombui, Florence \\ K Mutua \\ Department of Public Health, University of Nairobi, Kenya
}

Correspondence: Lydia Mageto, Department of Public Health, Pharmacology and Toxicology, Faculty of Veterinary medicine, University of Nairobi, P. O Box 29053, 00625 Nairobi, Kenya, Email lydiamageto@gmail.com

Received: anuary 07, 2018 | Published: February 19, 2018

\section{Introduction}

Campylobacter species are the most common cause of bacterial food borne disease affecting humans in both developed and developing countries. ${ }^{1}$ It is estimated that 400 to 500 million cases of Campylobacter enteritis occur annually around the world. ${ }^{2}$ Endocarditis, reactive arthritis, hemolytic uremic syndrome and septicemia are the complications that are occasionally seen., ${ }^{2,3}$ Rare complications such as meningitis, acute cholecystitis and Guillain Barré syndrome have been reported ${ }^{3,4}$ Human infections are mainly caused by Campylobacter jejuni and Campylobacter coli and rarely Campylobacter lari. ${ }^{5}$ There are many possible sources of Campylobacter infection in humans including contaminated poultry meat, ${ }^{6}$ untreated raw milk ${ }^{7}$ and contaminated water. ${ }^{8-10}$ The bacteria in the gastrointestinal tract of chicken and cattle can contaminate the carcass during slaughter and subsequently be transmitted to humans. ${ }^{2}$ Milk can be contaminated with Campylobacter in cattle faeces during milking, while water gets contaminated with chicken or cattle feaces from the environment. The main risk factor for human infection is consumption of raw or undercooked poultry meat contaminated with pathogenic Campylobacter species. ${ }^{11}$ Campylobacter species are carried in the intestinal tracts of birds and mammals which shed them in large numbers to contaminate the environment including water sources. ${ }^{12}$ Poultry meat is the most commonly incriminated cause of food borne Campylobacter infections occurring in humans in many parts of the world ${ }^{2}$ with fresh chicken as the main risk factor. ${ }^{13}$ Avian species especially domestic chickens are frequently infected primarily with Campylobacter Jejuni and Campylobacter coli during rearing. ${ }^{1,14}$ Campylobacter invade chicken early in life through contaminated drinking water, ${ }^{15,16}$ unhygienic chicken house environment, ${ }^{17}$ wild birds, flies and rodents. ${ }^{18}$ Risk factors that have been associated with Campylobacter colonization of chickens include season of the year, ${ }^{19}$ several poultry houses and presence of other animals in the farm. ${ }^{15}$ Contaminated drinking water, administration of antibiotics, ${ }^{15,20}$ poor hygiene, ${ }^{19,21,22}$ old age of the flock and that of houses at the farm ${ }^{22}$ have also been incriminated as risk factors for the infection. In order to reduce human infection, Campylobacter should be controlled at the farm level by preventing colonization of chicken gastrointestinal tract and subsequent shedding of the organisms during the rearing period. ${ }^{23}$ This can be done by maintaining good hygiene practices and implementation of appropriate biosecurity measures. ${ }^{23,24}$ These measures include acidification of drinking water and rodent control around the chicken houses. ${ }^{23}$ This will reduce contamination of carcasses during slaughter and ensure food safety. Data indicating the prevalence and risk factors associated with Campylobacter infections in poultry remains limited in Kenya. The aim of this study was to 
determine the prevalence of food borne Campylobacter pathogens in different chicken production systems in Nairobi's peri-urban areas and risk factors associated with observed prevalence at farm level. The findings of this study will be used in formulating strategies to control Campylobacter infection in poultry.

\section{Materials and methods}

The study was conducted in the peri-urban areas of Nairobi including Ruiru, Kikuyu and Ruai. These areas were selected because there are many poultry farmers who supply chicken and chicken products to the residents of Nairobi and surrounding areas according to Livestock Production officers report (2012).

\section{Study population and sampling design}

The target population was all chicken reared in peri-urban areas of Nairobi County between June and December 2015. The study population was chicken reared in Ruai, Ruiru and Kikuyu at the same period of study. A list of farms in the study areas was compiled at the start of the study with details such as the name of the farm and an estimate of the number of birds each farm had. The study farms were randomly selected from this list using randomly generated computer numbers. Data on the number of birds in each farm was used to classify farms into two levels (small scale and large scale production system). The areas were visited three days a week and during each visit three to four farms were visited for sample collection and administration of questionnaires. The number sampled in each level was proportional to the total number in the strata.

\section{Questionnaire}

A structured questionnaire was administered by the research team to the chicken farmer in each of farms visited during sample collection. The questionnaire had questions concerning: Age of poultry houses, age and number of birds in the houses, season of the year, source of water and water treatment, health status of the flock, type of litter used and bio-security and bio-safety practices at the farm.

\section{Sample collection and submission to the laboratory}

A stratified random sampling approach was then used to randomly sample live birds (from farms) for inclusion in the study. The sampling design was to allow for proportional sampling of birds at the individual farm level to ensure that each bird category the farmer had was represented (i.e. broilers, layers, indigenous chickens). Sterile cotton tipped swabs were used to obtain cloacal swabs which were then transported in Stuarts transport media to the laboratory within three hours after collecting the sample.

\section{Culture and isolation of Campylobacter}

Sterile cotton tipped swabs with cloacal fecal content were spread onto modified Charcoal Cefoperazone Deoxycholate Agar plates comprising of Campylobacter selective blood free agar base (CM0739, Oxoid, Basingstoke, U.K) and Camplobacter selective supplement (SR0167E, Oxoid, Basingstoke, U.K) containing cefoperazone 16mg, vancomycin $10 \mathrm{mg}$, sodium pyruvate $50 \mathrm{mg}$ and cycloheximide $50 \mathrm{mg}$ as selective supplements. The inoculated plates were incubated at $42^{\circ} \mathrm{C}$ for 48 hours under microaerophilic conditions created by using candles. After 48hours, suspect colonies of Campylobacter species were picked with a sterile wire loop and suspended in sterile distilled water in eppendorf tubes for DNA extraction. Campylobacter spp. suspect colonies were identified by colonial morphology, Gram stain, oxidase test and catalase test.

\section{Confirmation and identification of Campylobacter spe- cies}

This was done using a multiplex polymerase chain reaction (PCR) with primers described by Linton et al., ${ }^{25}$ Lawson et al. ${ }^{26}$ and Bang et al. ${ }^{27}$ listed in Table 1. DNA extraction was carried out using boiling method. A loopful of suspect Campylobacter colonies was suspended in $500 \mu 1$ of sterile distilled water in an eppendrof tube. It was boiled in a water bath at $100^{\circ} \mathrm{C}$ for 30 minutes. It was allowed to cool and centrifuged at $15000 \mathrm{rpm}$ for 5 minutes. The supernatant containing DNA was aliquot into a sterile eppendrof tubes for further tests. Multiplex PCR was performed in a total reaction volume of $12.5 \mu \mathrm{l}$ containing PCR master mix of $6.25 \mu 1$, and $0.05 \mu 1$ of $0.4 \mathrm{M}$ asp-primers $\mathrm{CC} 18 \mathrm{~F}$ and CC519R, ${ }^{25} 0.02 \mu 1$ of $0.2 \mathrm{M}$ hippurate based and $0.05 \mu 1$ of $0.05 \mathrm{M} 16 \mathrm{~S}$ rRNA based primers and $5 \mu 1$ of DNA template. Cycling conditions were initial denaturation at $94^{\circ} \mathrm{C}$ for $6 \mathrm{~min}$, followed by 35 cycles of denaturation at $94^{\circ} \mathrm{C}$ for $50 \mathrm{~s}$, annealing at $57^{\circ} \mathrm{C}$ for $40 \mathrm{~s}$ and extension at $72^{\circ} \mathrm{C}$ for $50 \mathrm{~s}$ and final heating $72^{\circ} \mathrm{C}$ for $3 \mathrm{~min}$. PCR products were analyzed using $1.5 \%$ agarose gel electrophoresis and stained with ethidium bromide. Results were documented by photography under UV light. Specific amplification fragments expected were of size $1062 \mathrm{bp}, 500 \mathrm{bp}$ and $344 \mathrm{bp}$ corresponded to Campylobacter genus, C. Coli and C. Jejuni respectively. The unit of observation was the individual bird and each sample represented an individual bird. If Campylobacter was detected by PCR in a sample, the bird was considered infected.

Table I Characteristics of primers used in the study

\begin{tabular}{|c|c|c|c|c|}
\hline Target species & Primer code & 5'............3' Primer sequence & Amplicon size(Bp) & Reference \\
\hline \multirow{3}{*}{ Campylobacter spp. } & I6S-F & GGAGGCAGCAGTAGGGAATA & \multirow{3}{*}{1062} & \multirow{3}{*}{27} \\
\hline & & & & \\
\hline & $16 S-R$ & TGACGGGCGGTGAGTACAAG & & \\
\hline \multirow{2}{*}{ C.coli } & \multirow{2}{*}{ CCI8F CC5I9R } & GGTATGATTTCTACAAAGCGA & \multirow{2}{*}{500} & \multirow{2}{*}{25} \\
\hline & & ATAAAAGACTATCGTCGCGTG & & \\
\hline \multirow{3}{*}{ C.jejuni } & hipO-F & GACTTCGTGCAGATATGGATGCTT & \multirow{3}{*}{344} & \multirow{3}{*}{27} \\
\hline & & & & \\
\hline & hipO-R & GCTATAACTATCCGAAGAAGCCATCA & & \\
\hline
\end{tabular}




\section{Analysis of risk factors}

Data from questionnaires was used to determine the most important risk factors associated with Campylobacter infection in chicken. This data were entered into Microsoft excel and checked for accuracy before being transferred to STATA Version 7. Logistic regression was used to determine the association between possible risk factors (explanatory variables) and Campylobacter status of the flock (outcome variable). Variables with a $p$-value $\leq 0.25$ in the univariate analysis were included in the multivariate logistic regression analysis

\section{Results}

\section{Prevalence of Campylobacter infection}

Campylobacter was isolated from 189 out of 272 birds sampled, giving a prevalence of $69.5 \%$. The prevalence of Campylobacter in broilers was $91.07 \%, 70.96 \%$ in layers and $61.04 \%$ in Indigenous chicken. Approximately $76.8 \%$ of the isolates from broilers were Campylobacter jejuni while $14.3 \%$ were neither Campylobacter coli nor Campylobacter jejuni. Of all the Campylobacter isolated from layers, $37.1 \%$ were C. Jejuni , $19.35 \%$ were C. Coli and $9.68 \%$ were neither $C$. Jejuni nor C. Coli. Approximately $32.5 \%$ of the isolates from indigenous chicken were C. Jejuni, 5.84\% were C. Coli and $15.58 \%$ were neither C. Jejuni nor C. Coli. Campylobacter jejuni was a predominant species of thermophilic Campylobacter $\mathrm{s}$ in all categories of chicken. Infection rate in chickens was significantly higher in broilers than layers and indigenous chicken. The results are shown in Table 2 below. The prevalence of Campylobacter infection of various chicken types from various study areas is given in Table 3.
The highest prevalence of $91.6 \%$ was recorded in Kikuyu, followed by Ruiru with a prevalence of $65.4 \%$ and Ruai with a prevalence of $55.9 \%$. The highest prevalence was recorded in layers $93.8 \%$, indigenous chicken $75 \%$ and broilers $97.14 \%$, from Kikuyu. The infection rate was lowest for broilers, layers and indigenous chicken from Ruai. Ruiru recorded moderate level of infection in broilers and indigenous chicken.

\section{Identification of risk factors}

Twelve variables were tested by univariate analysis and those that had a $\mathrm{p}$ value of $<0.25$ were considered to be significantly associated with Campylobacter infection. Six factors were associated with the infection with a $\mathrm{p}$ value less than 0.25 including age of poultry house $(p=0.23)$, number of birds kept $(p=0.12)$, age when birds were sold $(\mathrm{p}=0.01)$, type of rodent control $(\mathrm{p}=0.03)$, washing and disinfection of poultry house before restocking $(\mathrm{p}=0.004)$ and presence of a medicated footbath at the entrance into the poultry house $(\mathrm{p}=0.05)$ as shown in (Table 4) below. Almost all the farms had in place biosecurity measures. These included washing and disinfection of poultry houses before restocking, keeping birds of different species separately and maintaining the interval between two rearing periods at more than two weeks. Most of the farms had rodents and did not treat drinking water for the birds. The age of birds at the time of sampling was not statistically significant although there was evidence of increased odds of infection with increasing age of birds $(\mathrm{OR}=1.61)$. Presence of a medicated footbath at the entrance into the poultry house was highly significant with the risk of infection being 3.44 times higher in farms that lacked a medicated footbath.

Table 2 Prevalence of campylobacter infection in various chicken types

\begin{tabular}{|c|c|c|c|c|}
\hline $\begin{array}{l}\text { Species of } \\
\text { chicken }\end{array}$ & Campylobacter species & $\begin{array}{l}\text { No. of confirmed } \\
\text { Campylobacter } \\
\text { by PCR }\end{array}$ & Prevalence & $\begin{array}{l}95 \% \text { confidence } \\
\text { interval }\end{array}$ \\
\hline \multirow{5}{*}{$\begin{array}{l}\text { Broilers } \\
(n=56)\end{array}$} & Campylobacter spp & 51 & $91.07 \%$ & $83.6 \%-98.54 \%$ \\
\hline & Campylobacter jejuni & 43 & $76.79 \%$ & $65.73 \%-87.85$ \\
\hline & Campylobacter coli & 0 & 0 & 0 \\
\hline & C.jejuni and C.coli & 0 & 0 & 0 \\
\hline & Other campylobacter species & 8 & $14.29 \%$ & $5.12 \%-23.46 \%$ \\
\hline \multirow{5}{*}{$\begin{array}{l}\text { Layers } \\
(n=62)\end{array}$} & Campylobacter species & 44 & $70.96 \%$ & $59.66 \%-82.26 \%$ \\
\hline & C. jejuni & 23 & $37.10 \%$ & $25.08 \%-49.12 \%$ \\
\hline & C. coli & 12 & $19.35 \%$ & $9.55 \%-29.15 \%$ \\
\hline & C.jejuni and C.coli & 3 & $4.84 \%$ & -0.106 \\
\hline & Other Campylobacter species & 6 & $9.68 \%$ & $2.38 \%-16.98 \%$ \\
\hline \multirow{5}{*}{$\begin{array}{l}\text { Indigenous } \\
(n=154)\end{array}$} & Campylobacter species & 94 & $61.04 \%$ & $53.34 \%-68.74 \%$ \\
\hline & C. jejuni & 50 & $32.47 \%$ & $25.07 \%-39.87 \%$ \\
\hline & C. coli & 9 & $5.84 \%$ & $2.14 \%-9.54 \%$ \\
\hline & C.jejuni and C.coli & 7 & $4.55 \%$ & $1.25 \%-7.85 \%$ \\
\hline & Other Campylobacter species & 28 & $18.18 \%$ & $9.88 \%-21.28 \%$ \\
\hline $\begin{array}{l}\text { Total sample } \\
\text { size }(n=272)\end{array}$ & $\begin{array}{l}\text { Total number positive for Campylobacter } \\
\text { species }\end{array}$ & 189 & $69.50 \%$ & $64 \%-75 \%$ \\
\hline
\end{tabular}


Table 3 Prevalence of campylobacter infection of chicken from different study areas

\begin{tabular}{lllll}
\hline Study Area & Broilers & Layers & Indigenous Chicken & Total \\
\hline & No positive $(\%)$ & No positive $(\%)$ & No positive $(\%)$ & No positive (\%) \\
Ruai & $12 / 15(80 \%)$ & $14 / 30(46.7 \%)$ & $36 / 66(54.5 \%)$ & $62 / 111(55.9 \%)$ \\
Ruiru & $5 / 6(83.3 \%)$ & 0 & $46 / 72(63.9 \%)$ & $51 / 78(65.4 \%)$ \\
Kikuyu & $34 / 35(97.14 \%)$ & $30 / 32(93.8 \%)$ & $12 / 16(75 \%)$ & $76 / 83(91.6 \%)$ \\
Total & $51 / 56(91.07 \%)$ & $44 / 62(70.97 \%)$ & $94 / 154(61.04 \%)$ & $189 / 272(69.5 \%)$ \\
\hline
\end{tabular}

Table 4 Descriptive statistics of variables and univariable logistic regression analysis of risk factors for the occurrence of campylobacter species $(p<0.25)$ in 272 chicken in Nairobi, Kenya

\begin{tabular}{|c|c|c|c|c|}
\hline Variable & Level & No positive(\%) & P-value & Odds ratio \\
\hline \multirow{3}{*}{ Age of poultry house } & $>3$ years & $106(56.1)$ & \multirow{3}{*}{0.23} & \multirow{3}{*}{1.68} \\
\hline & & & & \\
\hline & $<3$ years & $83(43.9)$ & & \\
\hline \multirow{3}{*}{ Age of birds } & $>$ Imonth & $182(96.3)$ & \multirow{3}{*}{0.64} & \multirow{3}{*}{1.61} \\
\hline & & & & \\
\hline & $<$ Imonth & $7(3.7)$ & & \\
\hline \multirow{3}{*}{ Number of birds kept } & $>200$ & $43(22.8)$ & \multirow{3}{*}{0.12} & \multirow{3}{*}{0.4} \\
\hline & & & & \\
\hline & $<200$ & $146(77.2)$ & & \\
\hline \multirow{2}{*}{ Chicken mixing with other bird species } & Yes & $2 I(I I .1)$ & \multirow{2}{*}{0} & \multirow{2}{*}{0.11} \\
\hline & No & I68(88.9) & & \\
\hline \multirow{2}{*}{ Age when birds are sold } & $>$ |year(>35days for broilers & $121(64)$ & \multirow{2}{*}{0.01} & \multirow{2}{*}{0.32} \\
\hline & $<$ lyear(<35days for broilers) & $68(36)$ & & \\
\hline \multirow{2}{*}{ cleaning and disinfection of poultry house } & Yes & $170(90)$ & \multirow{2}{*}{0.004} & \multirow{2}{*}{0.11} \\
\hline & No & $19(10)$ & & \\
\hline \multirow[b]{2}{*}{ Length of down time } & $>2$ weeks & $121(64)$ & \multirow[b]{2}{*}{0.62} & \multirow[b]{2}{*}{1.3} \\
\hline & $<2$ weeks & $68(36)$ & & \\
\hline \multirow{2}{*}{ Presence of rodents } & Yes & | $44(76.2)$ & \multirow{2}{*}{0.99} & \multirow{2}{*}{ I } \\
\hline & No & $45(23.8)$ & & \\
\hline \multirow{4}{*}{ Type of rodent control } & Professional & $17(9)$ & \multirow{4}{*}{0.03} & \multirow{4}{*}{1.4} \\
\hline & Traps & $2(1.1)$ & & \\
\hline & Keeping cats & $109(57.7)$ & & \\
\hline & No control & $61(32.3)$ & & \\
\hline \multirow{2}{*}{ Presence of medicated footbath at entrance } & Yes & $49(26)$ & \multirow{2}{*}{0.05} & \multirow{2}{*}{3.44} \\
\hline & No & $140(74)$ & & \\
\hline & Rainwater & $24(12.7)$ & & \\
\hline & Borehole & $77(40.7)$ & & \\
\hline Source of drinking water for the chicken & Tap water & $62(32.8)$ & 0.66 & I.I \\
\hline & From water vendors & $22(11.6)$ & & \\
\hline & River water & $4(2.1)$ & & \\
\hline & Yes & $23(12.2)$ & & \\
\hline Use or treated arinking water & No & $166(87.8)$ & 0.39 & 0.65 \\
\hline
\end{tabular}




\section{Multivariable analysis}

The six variables that were significant in invariable analysis were screened using multivariable logistic regression analysis in a backward stepwise elimination procedure. Two factors remained in the model including age of poultry house $(\mathrm{p}=0.071)$ and house washing and disinfection before restocking $(\mathrm{p}=0.001)$ at a significance level of $\mathrm{p}<0.1$.

\section{Discussion}

This study reported a Campylobacter prevalence of $69.5 \%$ in chicken. The prevalence of Campylobacter in broilers was $91.07 \%$. The prevalence of Campylobacter infection in indigenous birds and layers was $61.04 \%$ and $70.96 \%$ respectively. Campylobacter jejuni was isolated from majority of the samples but few samples also yielded C. coli. A good number of chicken were also infected with other Campylobacter that were not identified. Our findings on the prevalence of Campylobacter are similar to the prevalence of $69.8 \%$ reported in chicken in Tanzania by Mdegela et al. ${ }^{28}$ However, it was higher than $51.5 \%$ reported from a study done in Kenya on apparently healthy domestic chicken by Turkson et al. ${ }^{13}$ On the other hand, the prevalence in broilers was higher than the $69 \%$ reported in Broiler flocks in Tanzania by Mdegela et al. ${ }^{28}$ Poor biosecurity measures including lower frequency of litter turning, inadequate sanitation and hygiene as well as poor spacing in the poultry houses enhances transmission of Campylobacter among broilers. This study also recorded a higher prevalence in indigenous chicken than $50.87 \%$ earlier reported in Kenya by $\mathrm{Ng}$ 'ethe et al., ${ }^{29}$ which was however lower than the prevalence of $71 \%$ reported in Tanzania. ${ }^{28}$ The observed high prevalence of Campylobacter infection of indigenous chicken in this study was attributed to poor management practices as they are perceived to be hardy compared to the exotic broilers and layers. A study done on the incidence of Campylobacter in laying hens in Sohag by Hedawey et al. ${ }^{30}$ reported an incidence rate of $38 \%$. However, this study found prevalence of $70.96 \%$ among layers. Campylobacter jejuni was the predominant Campylobacter species in broiler chicken with a prevalence of $61.4 \%$. This was consistent with other studies ${ }^{22,31}$ but inconsistent with a study done in Thailand by Padungtod et al. ${ }^{32}$ where $C$. Coli was reported to be the predominant Campylobacter species in broilers chicken. This study did not find any C. Coli in broiler chickens.

This study identified the following risk factors for Campylobacter colonization in chicken. They include failure to use footbath with disinfectant, old age of poultry house, and inadequate house cleaning and disinfection before restocking. Previous studies also identified poor quality of drinking water, ${ }^{9,1} 0$ unhygienic conditions of poultry houses ${ }^{21}$ presence of other animals such as rodents in the farm ${ }^{15}$ as risk factors of Campylobacter colonization. A study done by Humphrey et al. ${ }^{19}$ showed a decrease in Campylobacter colonization of chicken with increased use of disinfected footbaths. The frequency of changing the disinfectant in the footbath has an effect on the level of infection. Changing the disinfectant twice weekly reduced the risk of infection in flocks according to an intervention trial done by Gibbens et al. ${ }^{33}$ Weekly change of disinfectant would also reduce the infection risk according to a report by Evans et al. ${ }^{21}$ Old age of poultry house was also a significant factor with houses more than three years having a higher odds of infection than those less than 3years $(\mathrm{p}=0.071, \mathrm{OR}=1.91)$. This was possibly due to contamination from previous flocks. Old houses more than three years are associated with poor state of repair and maintenance of the poultry house that encouraged large rodent populations which are reservoirs for Campylobacter infection.

The main risk factor associated with the Campylobacter infection in this study was lack of house cleaning and disinfection before restocking $(\mathrm{p}=0.001, \mathrm{OR}=0.28)$. Chickens reared in houses that were adequately cleaned and disinfected were 3.6 times less likely to get Campylobacter infection compared to those not adequately cleaned and disinfected. This observation was consistent with the observations made by Evans and Sayers ${ }^{21}$ on the role of biosecurity measures and hygiene in reducing Campylobacter infection in poultry. However, Nather et al..$^{34}$ Annan-Prah $\mathrm{A}^{35}$ Osano $\mathrm{O}^{36}$ Huneau-Salaun A et al. ${ }^{37}$ Scallan E et al. ${ }^{38}$ reported no effect of biosecurity measures and hygiene on the level of Campylobacter infection. The carryover of infection from a previous Campylobacter infected flock to a new flock in the same house is a potential source of Campylobacter infection. This is particularly important in farms where used litter is routinely left in the houses between crops. Prevalence of Campylobacter in chicken in this study was relatively high. The most significant risk factors were increasing age of poultry houses and inadequate cleaning and disinfection of poultry houses before restocking. Controlling Campylobacter infection during rearing could reduce contamination during the later stages of production and ensure food safety. Strict biosecurity measures should therefore be put in place to reduce the risk of infection during chicken rearing.

\section{Acknowledgements}

We wish to express our gratitude to The University of Nairobi for allowing us to use their research laboratory. The co-operation of farmers and field staff is highly appreciated. We also acknowledge the grant support from Kenya's National Council for Science Technology and Innovations (NACOSTI) that enabled us do this work in collaboration with the University of Pretoria, Ondersterpoort Campus through a grant from South African National Research Foundation (NRF).

\section{Conflicts of interest}

Author declares that there is no conflict of interest.

\section{References}

1. Sahin O, Morishita TY, Zhang Q. Campylobacter colonization in poultry: Sources of infection and modes of transmission. Anim Health Res Rev. 2002;3(2):95-105.

2. Friedman CR, Neimann J, Wegener HC, et al. Epidemiology of Campylobacter jejuni infections in the United States and other industrialized nations. In Campylobacter. 2nd ed. In: Nachamkin I, Blaser MJ, editors. American Society for Microbiology. USA; 2000. p. 121-138.

3. Nachamkin I, Allos BM, Ho T. Campylobacter species and Guillain Barre Syndrome. Clin Microbiol Rev. 1998;11(3):555-567.

4. Blaser MJ. Epidemiologic and clinical features of Campylobacter jejuni infections. J Infect Dis. 1997;176(2):103-105.

5. Centers for Disease Control and Prevention [CDC]. Campylobacter: general information. 2013.

6. Wingstrand A, Neimann J, Engberg J, et al. Fresh chicken as the main risk factor for Campylobacteriosis, Denmark. Emerg Infect Dis. 2000;12(2):280-284.

7. Peterson MC. Campylobacter jejuni enteritis associated with consumption of raw milk. J Environ Health. 2003;65(9):20-21. 
8. Abe T, Haga S, Yokoyama K, et al. An outbreak of Campylobacter jejun subsp jejuni infection via tap water. J Infect Dis. 2008;61(4):327.

9. Diergaardt SM, Venter SN, Spreeth A, et al. The occurrence of campylobacters in water sources in South Africa. Water Res. 2004;38(10):2589-2595.

10. Jones K. Campylobacters in water, sewage and the environment. Symp Ser Soc Appl Microbiol. 2001;30:68S-79S.

11. McDowell SW, Menzies FD, McBride SH, et al. Campylobacter species in conventional broiler flocks in Northern Ireland: Epidemiology and risk factors. Prev Vet Med. 2008;84(3-4):261-276.

12. Dechesne M, Soveus E. Assessment of source water pathogen contamination. $J$ Water Health. 2007;5(1S):39-50

13. Turkson PK, Lindqvist KJ, Kapperud G. Isolation of Campylobacter spp. and Yersinia enterocolitica from domestic animals and human patients in Kenya. APMIS. 1988;96(2):141-146.

14. Datta S, Niwa H, Itoh K. Age-dependent variation of virulence associated genes in Campylobacter jejuni from chickens in a poultry farm. $J$ Vet Med Sci. 2009;71(9):1247-1249.

15. Refrégier-Petton J, Rose N, Denis M, et al. Risk factors for Camplobacter spp. contamination of French broiler chicken flocks at the end of the rearing period. Prev Vet Med. 2001;50(1-2):89-100.

16. Sparks HNC. The role of the water supply system in the infection and control of Campylobacter in chicken. World Poultry Sci J. 2000;65(3):450-474.

17. Lee MD, Sanchez S, Zimmer M, et al. Class 1 intergron-associated tobramycin-gentamycin resistance in Campylobacter jejuni isolated from broiler chicken house environment. Antimicrob Agents Chemother. 2002;46(11):3660-3664

18. Gregory E, Barnhart H, Dreesen DW, et al. Epidemiological study of Campylobacter species in broilers: source, time of colonization and prevalence. Avian Dis. 1997;41(4):890-898.

19. Humphrey TJ, Henley A, Lanning DG. The colonization of broiler chickens with Campylobacter jejuni: some epidemiological investigations. Epidemiol Infect. 1993;110(3):601-607.

20. Ansari-Lari M, Hosseinzadeh S, Shekarforoush SS, et al. Prevalence and risk factors associated with campylobacter infections in broiler flocks in Shiraz, Southern Iran. Int J Food Microbiol. 2011;144(3):475-479.

21. Evans SJ, Sayers AR. A longitudinal study of campylobacter infection of broiler flocks in Great Britain. Prev Vet Med. 2000;46(3):209-223.

22. Bouwknegt M, van de Giessen AW, Dam-Deisz WD, et al. Risk factors for the presence of Campylobacter spp. In Dutch broiler flocks. Prev Vet Med. 2004;62(1):35-49.

23. Allain V, Chemaly M, Laisney MJ, et al. Prevalence and risk factors for Campylobacter colonization in broiler flocks at the end of the rearing period in France. Br Poult Sci. 2014;55(4):452-459.
24. Tablante NL, Myint MS, Johnson YJ, et al. A survey of biosecurity practices as risk factors affecting broiler performance on the Delmarva Peninsula. Avian Dis. 2002;46:730-734.

25. Linton D, Owen RJ, Stanley J. Rapid identification by PCR of the genus Campylobacter and of five Campylobacter species enteropathogenic for man and animals. Res Microbiol. 1996;147(9):707-718

26. Lawson AJ, Linton D, Stanley J. 16S rRNA gene sequences of Candidatus Campylobacter hominis, a novel uncultivated species, are found in the gastrointestinal tract of healthy humans. Microbiol. 1998;144(8):2063-2071.

27. Bang DD, Nielsen EM, Knudsen K, et al. A one year study of campylobacter carriage by individual Danish broiler chickens as the basis for selection of Campylobacter species strains for a chicken infection model. Epidemiol Infect. 2003;130(2):320-323.

28. Mdegela RH, Nonga HE, Ngowi HA, et al. Prevalence of thermophilic Campylobacter infections in humans, chickens and crows in Morogoro, Tanzania. J Vet Med B Infect Dis Vet Public Health . 2006;53(3):116-121.

29. Ngethe EW. Prevalence of selected Zoonotic and contaminant bacteria Master of Veterinary Public Health Thesis, University of Nairobi; 2015.

30. Hedawey KHAA, Youssef AA. Incidence of Campylobacter species in laying hens and table eggs in Sohag Governorate. Assiut Vet Med J. 2014;60(141):120-124.

31. Ghafir Y, China B, Dierick K, et al. A seven-year survey of Campylobacter contamination in meat at different production stages in Belgium. Int J Food Microbiol. 2007;116(1):111-120.

32. Padungton P, Kaneene JB. Campylobacter species in human, chickens, pigs and their antimicrobial resistance. $J$ Vet $\mathrm{Med} \mathrm{Sci}$. 2003;65(2):161-170

33. Gibbens JC, Pascoe SJ, Evans SJ, et al. sA trial of biosecurity as a means to control campylobacter infection of broiler chickens. Prev Vet Med. 2001;48(2):85-99.

34. Näther G,Alter T, Martin A, et al. Analysis of risk factors for campylobacter species infection in broiler flocks poultry. Sci. 2009;88(6):1299-1305

35. Annan-Prah A, Janc M. The mode of spread of Campylobacter jejuni/ coli to broiler flocks. Zentralbl Veterinarmed B. 1988;35:11-18.

36. Osano O, Arimi SM. Retail poultry and beef as sources of campylobacter jejuni. East Afr Med J. 1999;76(3):141-143.

37. Huneau-Salaun A, Denis M, Balaine L, et al. Risk factors for Campylobacter species colonization in French free-range broiler chicken flocks at the end of the indoor rearing period. Prev Vet Med. 2007;80(1):34-48.

38. Scallan E, Hoekstra RM, Angulo FJ, et al. Food borne illness acquired in the United States - major pathogens. Emerg Infect Dis. 2011;17(1):7-15. 